\title{
Reply to Comment on “On Humbert Matrix Polynomials of Two Variables"
}

\author{
Ghazi S. Khammash1, Ayman Shehata ${ }^{2,3}$ \\ ${ }^{1}$ Department of Mathematics, Al-Aqsa University, Gaza Strip, Palestine \\ ${ }^{2}$ Department of Mathematics, Faculty of Science, Assiut University, Assiut, Egypt \\ ${ }^{3}$ Department of Mathematics, College of Science and Arts in Unaizah, Qassim University, Qassim, KSA \\ Email: ghazikhamash@yahoo.com, drshehata2006@yahoo.com
}

Received 5 May 2014; revised 25 June 2014; accepted 2 July 2014

Copyright (C) 2014 by authors and Scientific Research Publishing Inc.

This work is licensed under the Creative Commons Attribution International License (CC BY).

http://creativecommons.org/licenses/by/4.0/

cC) (i) Open Access

\section{Abstract}

The formula subject to comment in Reference [1] is correct.

\section{Keywords}

\section{Matrix Functions, Humbert Matrix Polynomials}

\section{Introduction and Motivation}

This reply is written as an answer to the paper [2] [3].

In the comment [2], the author points out that the generating matrix function given in Formula (7) in our recently published paper [1]

$$
\left(1-\left(m x t-t^{m}\right)-\left(m y s-s^{m}\right)\right)^{-A}=\sum_{n=0}^{\infty} \sum_{k=0}^{\infty} p_{n, k, m}(x, y, A) t^{n} s^{k}
$$

is not true, because the domain is not clarified. And the author notes, that $\left(1-\left(m x t-t^{m}\right)-\left(m y s-s^{m}\right)\right)$

for that it can be zero, and then it is meaningless. Further he writes: "For this, first we have to observe that for matrix $A$, we define $t^{A}=\mathrm{e}^{A \log (t)}$ where $\mathrm{e}^{B x}$ is the exponential matrix. Of course, $t^{A}$ has sense only for $t \neq 0$ ". To clarify the situation, let us write down the relation for any matrix $P$ in $C^{N \times N}$ the following relation

$$
(1-z)^{-p}=\sum_{n=0}^{\infty} \frac{(p)_{n} z^{n}}{n !}, \quad|z|<1
$$


holds [4] (see also [5] [6]). From above we maintain that $\left[(1-z)^{-A}=e^{A \log (1-z)}\right.$ thus $\left.1-z \neq 0\right]$, from above and from (1) we conclude our reply by noting that the relation ( Humbert matrix polynomials of two variables (7) [1]) is generated by

$$
\begin{aligned}
& \left(1-\left(m x t-t^{m}\right)-\left(m y s-s^{m}\right)\right)^{-A}=\sum_{n=0}^{\infty} \sum_{k=0}^{\infty} p_{n, k, m}(x, y, A) t^{n} s^{k} \\
& \left(A \in C^{N \times N},\left|\left(m x t-t^{m}\right)+\left(m y s-s^{m}\right)\right|<1\right)
\end{aligned}
$$

where $m$ is positive integer.

In paper [3] the author notes that in "Remark" comments that the double generating Formula (8) [7]

$$
\left(1-\left(2 x t-t^{2}\right)-\left(2 y s-s^{2}\right)\right)^{-A}=\sum_{n=0}^{\infty} \sum_{k=0}^{\infty} C_{n, k}^{A}(x, y, A) t^{n} s^{k}
$$

is not true. We conclude our reply by noting that we consider our relation (8) with the help of (1) provided that $\left|\left(2 x s-s^{2}\right)+\left(2 y t-t^{2}\right)\right|<1$ and not equal 1. Note that, in a variety of different research papers our own paper it has been written with approximate resemblance with other papers in the methods, for example, Dattoli et al. [8] and Pathan and Khan [9]. In conclusion, we accept blame for not clarifying the domain because this perhaps causes misunderstanding for readers who are not totally familiar with literature in this area. However, note that even accepting Soler interpretation, from (1) which is written in [1] [7] and it is not mentioned in Soler comments [2] [3], the conjecture counter examples remain false in [2] [3]. However, our results are original and correct.

\section{AMS 2010 Subject Classification}

Primary 33C45, 15A15. Secondary 33C45, 15A60

\section{References}

[1] Khammash, G.S. and Shehata, A. (2012) On Humbert Matrix Polynomials of Two Variables. Advances in Pure Mathematics, 2, 423-427. http://dx.doi.org/10.4236/apm.2012.26064

[2] Basauri, V.S. (2013) A Comment on “On Humbert Matrix Polynomials of Two Variables”. Advances in Pure Mathematics, 3, 470-471. http://dx.doi.org/10.4236/apm.2013.35066

[3] Basauri, V.S. (2013) A Study of a Two Variables Gegenbauer Matrix Polynomials and Second Order Matrix Partial Differential Equations. A comment. International Journal of Mathematical Analysis, 7, 973-976.

[4] Jódar, L., Company, R. and Ponsoda, E. (1995) Orthogonal Matrix Polynomials and Systems of Second Order Differential Equations. Differential Equations and Dynamical Systems, 3, 269-288.

[5] Jódar, L. and Cortés, J.C. (1998) On the Hypergeometric Matrix Functions. Journal of Computational and Applied Mathematics, 99, 205-217. http://dx.doi.org/10.1016/S0377-0427(98)00158-7

[6] Aktas, R., Cekim, B. and Sahin, R. (2012) The Matrix Version for the Multivariable Humbert Polynomials. Miskolc Mathematical Notes, 13, 197-208.

[7] Kahmmash, G.S. (2008) A Study of a Two Variables Gegenbauer Matrix Polynomials and Second Order Matrix Partial Differential Equations. International Journal of Mathematics Analysis, 2, 807-821.

[8] Dattoli, G., Ricci, P.E. and Srivastava, H.M. (2003) Two-Index Multidimensional Gegenbauer Polynomials and Their Integral Representations. Mathematical and Computer Modelling, 37, 283-291. http://dx.doi.org/10.1016/S0895-7177(03)00006-2

[9] Pathan, M.A. and Khan, M.A. (1997) On Polynomials Associated with Humbert's Polynomials. Publ. Inst. Math. (Beograd) (N.S.), 67, 53-62. 
Scientific Research Publishing (SCIRP) is one of the largest Open Access journal publishers. It is currently publishing more than 200 open access, online, peer-reviewed journals covering a wide range of academic disciplines. SCIRP serves the worldwide academic communities and contributes to the progress and application of science with its publication.

Other selected journals from SCIRP are listed as below. Submit your manuscript to us via either submit@scirp.org or Online Submission Portal.
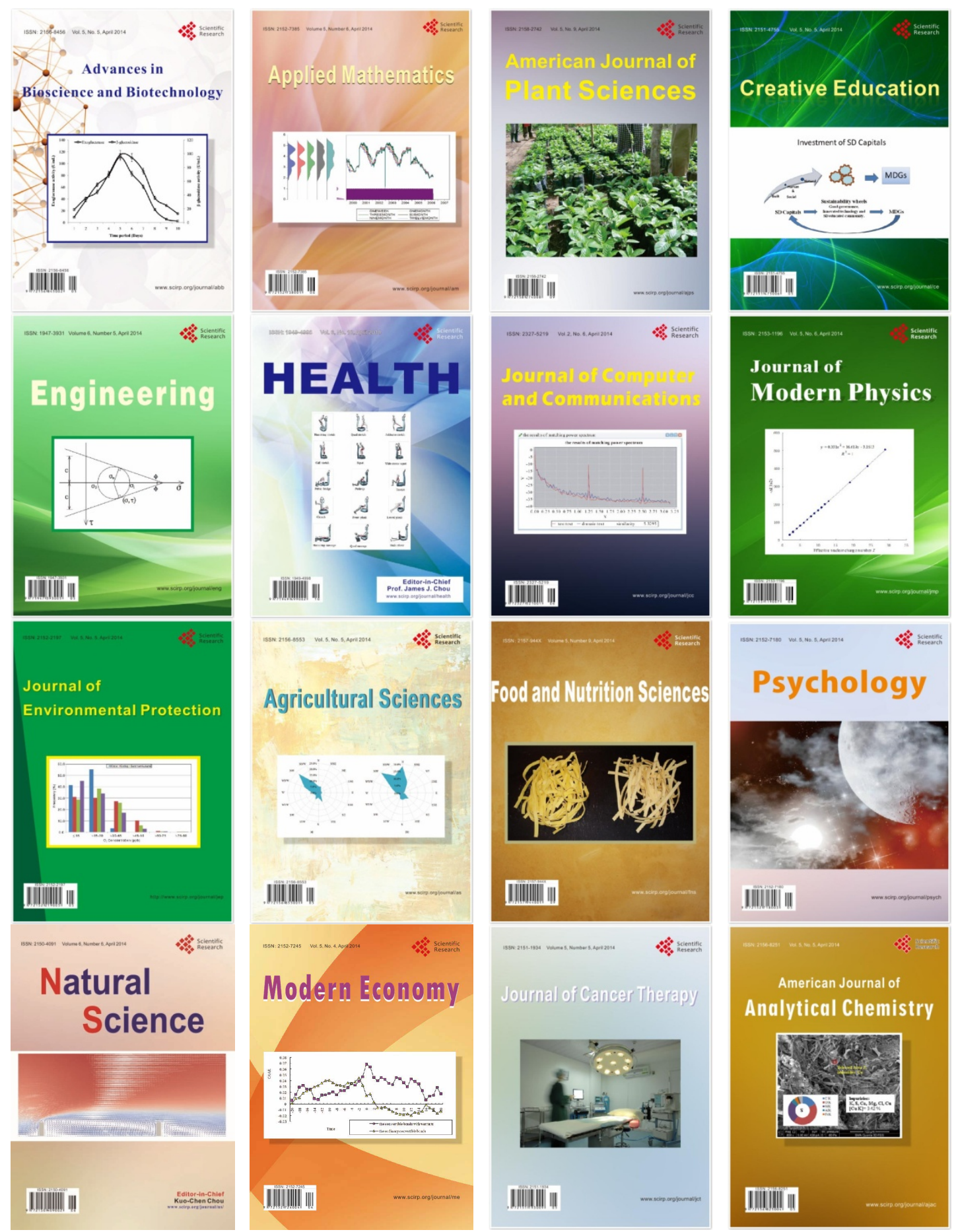